\title{
Molecular Beam Epitaxial Regrowth of Antimonide-Based Semiconductors
}

\author{
MATTHEW REASON, ${ }^{1}$ BRIAN R. BENNETT, ${ }^{1,2}$ RICHARD MAGNO, ${ }^{1}$ \\ and J. BRAD BOOS ${ }^{1}$ \\ 1.-Electronics Science and Technology Division, Naval Research Laboratory, Washington, \\ DC 20375, USA. 2.—e-mail: brian.bennett@nrl.navy.mil
}

\begin{abstract}
We have investigated regrowth of $p^{+}$InGaSb on AlGaSb and on thin InAs etch-stop layers after atomic hydrogen cleaning (AHC) surface treatments. Following certain cleaning conditions, the surface morphologies for $\mathrm{In}_{0.27} \mathrm{Ga}_{0.73} \mathrm{Sb}$ regrown on InAs exhibit smooth surfaces with similar rootmean-square (rms) roughness to the as-grown InAs, which in turn is similar to the roughness of the AlGaSb buffer layer below it. In addition, hole mobilities for InGaSb regrown on AHC InAs approach the highest mobilities reported to date for any $p^{+}$III-V semiconductors. A wide range of AHC conditions including substrate temperatures from $280^{\circ} \mathrm{C}$ to $370^{\circ} \mathrm{C}$ and exposure durations between $5 \mathrm{~min}$ and $30 \mathrm{~min}$ result in smooth InGaSb films with low resistivity.
\end{abstract}

Key words: InGaSb, regrowth, overgrowth, MBE, $p$-FET, AFM, antimonide, InAs, AlGaSb

\section{INTRODUCTION}

In recent years, there has been considerable interest in the antimonide-arsenide materials systems, for applications including high-electronmobility transistors (HEMTs), heterojunction bipolar transistors, and $\mathrm{THz}$ subharmonic mixers., InGaSb channel materials with a lattice parameter near $6.2 \AA$ are of particular interest, since these have the highest hole mobilities of all III-V semiconductors, as well as high conduction and valence band offsets with lattice-matched InAlSb barrier layers. ${ }^{3}$ To incorporate high-speed, low-power Sb-based HEMTs into advanced logic circuits, a complementary $p$-channel field-effect transistor $(p$-FET) is required. Recently, the fabrication and characterization of InGaSb-channel $p$-FETs have been reported. ${ }^{4}$ However, reduction of the contact and access resistances is necessary for further improvement in high-speed, low-power performance. ${ }^{4}$

One approach to lowering the contact and access resistances involves epitaxial regrowth. A

(Received September 27, 2010; accepted October 6, 2010; published online November 11, 2010) cross-section of a potential device, showing the material layer design, is given in Fig. 1. In this approach, the $p$-FET heterostructure would be grown, then removed from vacuum and processed, followed by reloading into the reactor for $p^{+} \mathrm{InGaSb}$ regrowth in the source and drain regions. To date, there have been few studies of regrowth for Sbbased materials. ${ }^{5-7}$ Many challenges still persist, including understanding the surface preparation necessary to remove oxides and residues that impede regrowth. Atomic hydrogen cleaning (AHC) has been utilized for removing oxides and hydrocarbons from a variety of polar III-V semiconductor surfaces, ${ }^{8}$ and has improved results for regrowth on (In)GaAs surfaces, ${ }^{9-11}$ but its effectiveness for Sb-based regrowth remains unexplored.

In this article, we report successful fabrication of high-quality $p^{+}$InGaSb regrowth layers, which was achieved by inserting a thin InAs layer after the $\mathrm{AlGaSb}$ buffer layer in Fig. 1 to avoid regrowth on the Al-containing buffer layer. While AHC proved ineffective for regrowth on AlGaSb, we achieved low-resistance InGaSb regrowth layers on InAs which was cleaned using a wide range of substrate temperatures and duration times. 


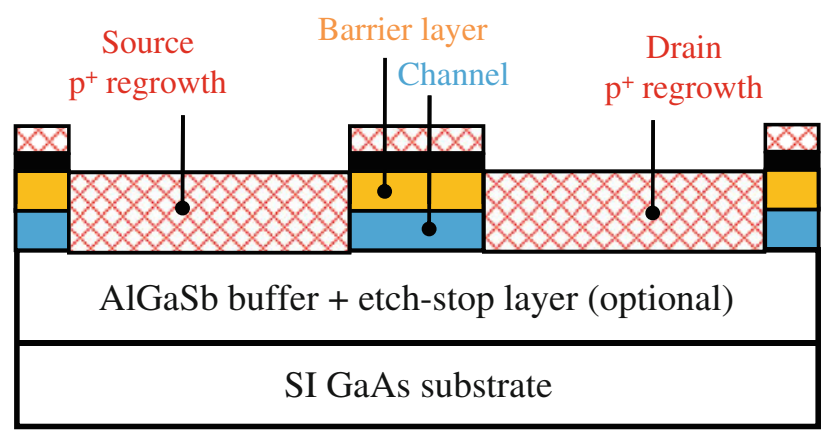

Fig. 1. (Color online). Cross-section of a $p$-type field-effect transistor device, utilizing $p^{+}$regrowth (shown in red cross-hatching) to reduce the contact and access resistances for the source and drain contacts. The channel, barrier, and sacrificial protection layers are shown in blue, orange, and black, respectively.

\section{EXPERIMENTAL PROCEDURES}

The samples reported in this work were grown by solid-source molecular-beam epitaxy (MBE) with valved sources for $\mathrm{As}_{2}$ and $\mathrm{Sb}_{2}$. Be was used as the $p$-type dopant. Ternary compositions were controlled by monitoring intensity oscillations on test structures with reflection high-energy electron diffraction (RHEED), and confirmed by x-ray diffraction measurements. Flux measurements were used to set the valves of the group $\mathrm{V}$ sources to produce a ratio of V/III incorporation rates of $\sim 1.5: 1$. A growth rate of one monolayer per second (ML/s) was used for each layer, unless otherwise noted. During growth, surface reconstructions and substrate temperatures were monitored using RHEED and a k-Space Associates BandiT band-edge thermometry system, respectively. Prior to InGaSb regrowth, AHC was performed using a $1.0 \mathrm{sccm}$ hydrogen flow rate, in a chamber with a base pressure of $\sim 5 \times 10^{-10}$ Torr. During AHC, the chamber pressure was $2.3 \times$ $10^{-5}$ Torr, with dose times of 5 min to $60 \mathrm{~min}$, corresponding to estimated $\mathrm{H}_{2}$ doses of 7 kilolangmuirs to 80 kilolangmuirs. Substrate temperatures during AHC were estimated by calibrating the MBE chamber manipulator thermocouple reading with the BandiT temperature measurement, and assuming that the nominally identical heaters and thermocouples in the MBE and AHC chambers function the same.

For the initial growths, epiready (001) semiinsulating GaAs substrates were cleaved and mounted in $2 \mathrm{~cm} \times 2 \mathrm{~cm}$ square In-free plates. As there are no commercially available semi-insulating substrates with a $6.2 \AA$ lattice constant, a $1 \mu \mathrm{m}$ $\mathrm{Al}_{0.7} \mathrm{Ga}_{0.3} \mathrm{Sb}$ buffer layer with a lattice constant of $\sim 6.12 \AA$ was grown at $530^{\circ} \mathrm{C}$ to help accommodate the lattice mismatch between the GaAs substrate and the InGaSb regrowth epilayer. For samples which contained an etch-stop layer, the substrate temperature was lowered to $500^{\circ} \mathrm{C}$ and a $25 \AA$ InAs etch-stop layer was grown at $0.2 \mathrm{ML} / \mathrm{s}$. Finally, the sample was quenched to room temperature, removed from vacuum, and stored in room air for a period of approximately 1 month. No ex situ surface treatments were used except where noted. Instead, in situ $\mathrm{AHC}$ was performed for $5 \mathrm{~min}$ to $60 \mathrm{~min}$ at substrate temperatures between $280^{\circ} \mathrm{C}$ and $400^{\circ} \mathrm{C}$, to remove the native oxide and other contaminants. Following AHC, samples were transferred under ultrahigh vacuum (UHV) to the MBE chamber and heated to $400^{\circ} \mathrm{C}$. Then, a $235 \AA p$-type $\mathrm{In}_{0.27} \mathrm{Ga}_{0.73} \mathrm{Sb}$ layer was regrown with a target dopant density of $\sim 3 \times 10^{19} \mathrm{~cm}^{-3}$. The surface morphology of the InGaSb films was examined ex situ with tapping-mode atomic force microscopy (AFM) ${ }^{12}$ Electronic transport measurements were implemented in the van der Pauw geometry using $5 \mathrm{~mm} \times 5 \mathrm{~mm}$ pieces and In solder contacts. Hall measurements were performed at magnetic fields of $0.37 \mathrm{~T}, 0.55 \mathrm{~T}$, and $1.0 \mathrm{~T}$, for two or more currents at each $B$ field.

\section{MEASUREMENT, RESULTS, AND ANALYSIS}

Figure 1 illustrates the desired $p$-FET structure including regrowth of $p^{+}$InGaSb for the source and drain contacts. In this section, we investigate the simpler case of $p^{+}$InGaSb regrowth directly on the AlGaSb buffer, with no FET structure involved. Figure 2 shows representative $10 \mu \mathrm{m} \times 10 \mu \mathrm{m}$ AFM images of InGaSb regrown on AlGaSb following (a) 5 min $\mathrm{AHC}$ at $370^{\circ} \mathrm{C}$, and (b) ex situ $\mathrm{HCl}$ dip and $30 \mathrm{~min} \mathrm{AHC}$ at $300^{\circ} \mathrm{C}$. For regrowth on AlGaSb which was not treated with $\mathrm{HCl}$, a diffuse RHEED pattern was observed throughout the InGaSb growth, indicating that AHC was not sufficient to remove the aluminum-containing oxide. Qualitative analysis of multiple AFM images reveals multilayer growth for all InGaSb regrowths on $\mathrm{AlGaSb}$, with an $\mathrm{rms}$ roughness of (a) $10 \mathrm{~nm}$ with no ex situ surface treatments and (b) $20 \mathrm{~nm}$ with $\mathrm{HCl}$ dip to remove oxide before AHC. For InGaSb regrown on AlGaSb, the resistivity was too high $\left(>10^{6} \Omega / \square\right)$ to determine the Hall mobilities accurately.

In order to avoid regrowth directly on $\mathrm{AlGaSb}$, an additional layer must be inserted after the AlGaSb buffer. The material for this layer must have a lattice parameter relatively close to that of AlGaSb, without containing Al. Thus, the potential binary materials for such a layer are limited to InAs or GaSb. We have successfully regrown smooth InGaSb layers on $\mathrm{GaSb}$, but regrowth on a thin GaSb layer is not applicable to the $p$-FET structure shown in Fig. 1, since it is not a suitable etch-stop layer. Instead, InAs was chosen, since a thin layer can be inserted between the AlGaSb buffer layer and InGaSb channel shown in Fig. 1, enabling a selective etch of the Sb-based layers above. Furthermore, $25 \AA$ InAs can be inserted as an etch-stop layer without creating a parallel conduction channel. ${ }^{13}$ Therefore, we investigated $p^{+}$InGaSb regrowth on $\mathrm{AlGaSb}$ capped with $25 \AA$ InAs, for a variety of AHC temperatures and cleaning durations. 


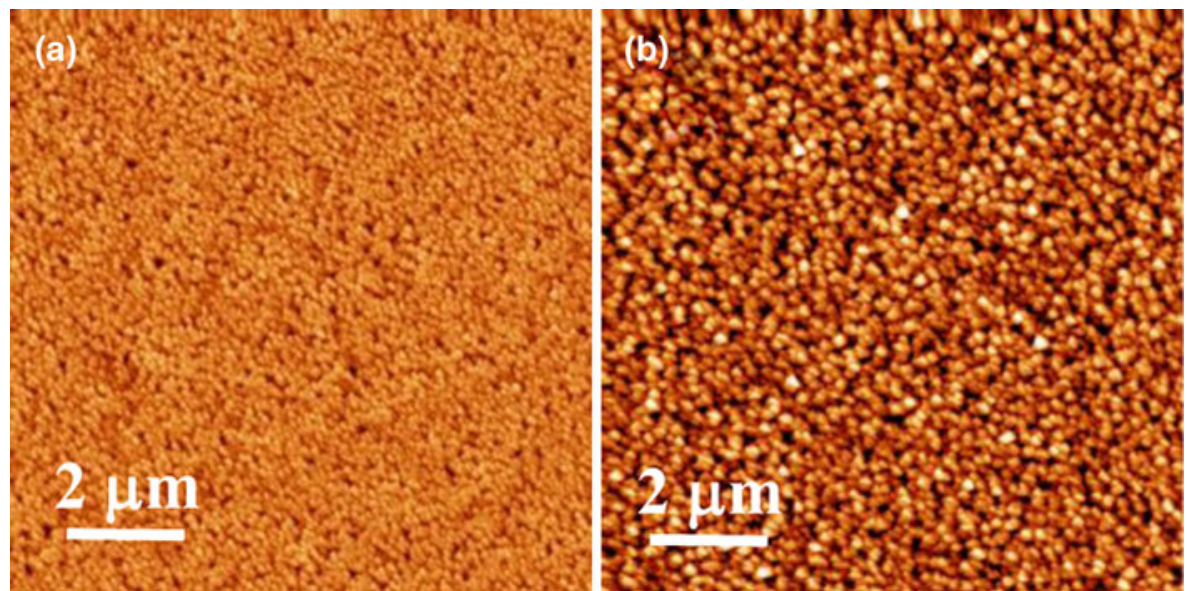

Fig. 2. Representative $10 \mu \mathrm{m} \times 10 \mu \mathrm{m}$ AFM images of $p^{+}$InGaSb regrowth directly on AIGaSb, following (a) 5 min atomic hydrogen cleaning at $370^{\circ} \mathrm{C}$, and (b) $\mathrm{HCl}$ dip plus $30 \mathrm{~min}$ atomic hydrogen cleaning at $300^{\circ} \mathrm{C}$. The gray-scale range displayed is $100 \mathrm{~nm}$ for both images.
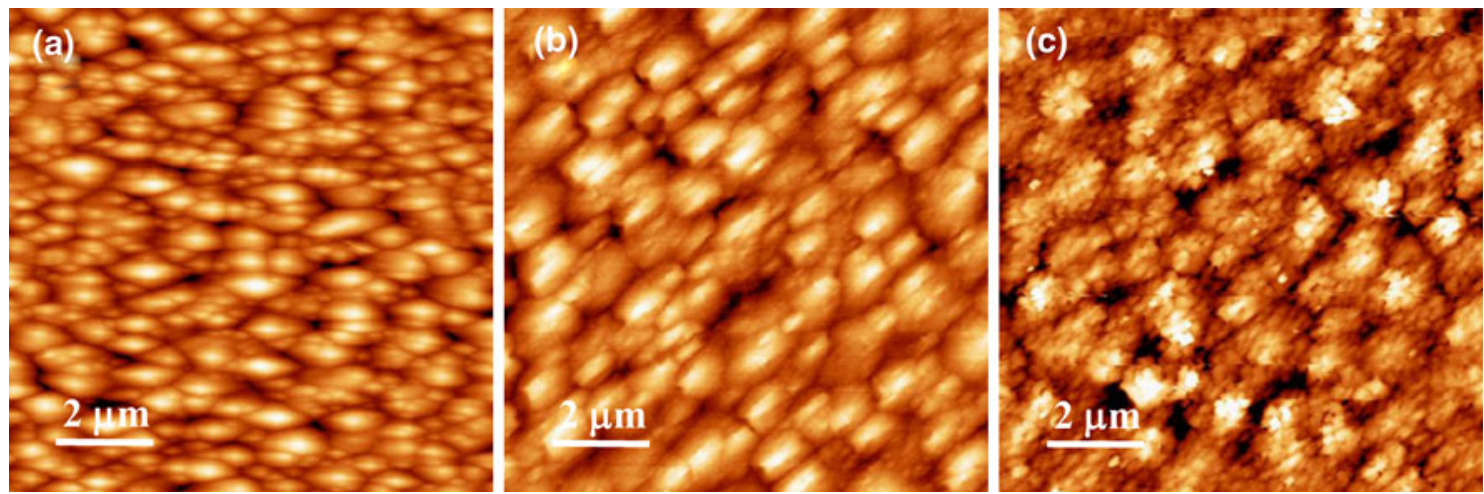

Fig. 3. Representative $10 \mu \mathrm{m} \times 10 \mu \mathrm{m}$ AFM images of (a) as-grown InAs on AIGaSb, and $p^{+}$InGaSb regrowth on InAs following 5 min of atomic hydrogen cleaning at (b) $350^{\circ} \mathrm{C}$, and (c) $400^{\circ} \mathrm{C}$. The gray-scale range displayed is $10 \mathrm{~nm}$ for all images.

For InGaSb regrowth on InAs, AHC was performed between $280^{\circ} \mathrm{C}$ and $400^{\circ} \mathrm{C}$, for 5 min to $60 \mathrm{~min}$. Immediately following hydrogen cleaning, the sample was transferred under UHV to the MBE chamber and examined with RHEED. For the majority of samples, RHEED revealed a streaky $(2 \times 4)$ surface reconstruction for InAs after AHC, in contrast to the diffuse RHEED pattern observed from the oxide-covered InAs before AHC. However, for $\mathrm{AHC}$ performed at $400^{\circ} \mathrm{C}$ or for $60 \mathrm{~min}$ at $350^{\circ} \mathrm{C}$ to $370^{\circ} \mathrm{C}$, RHEED revealed a spotty $(1 \times 1)$ pattern, suggesting that the surface may be heavily damaged during hydrogen cleaning at high temperatures and/or long exposure times.

Figure 3 shows representative $10 \mu \mathrm{m} \times 10 \mu \mathrm{m}$ AFM images of InGaSb regrown on InAs following 5 min $\mathrm{AHC}$ at $350^{\circ} \mathrm{C}$ (Fig. $3 \mathrm{~b}$ ) and $400^{\circ} \mathrm{C}$ (Fig. 3c). For comparison, the surface morphology of InAs is shown in Fig. 3a, before InGaSb regrowth. For InGaSb regrowth on InAs cleaned between $280^{\circ} \mathrm{C}$ and $370^{\circ} \mathrm{C}$, including Fig. $3 \mathrm{~b}$, we observe an AFM rms roughness of $1.6 \mathrm{~nm}$ with a peak-to-valley height of $12 \mathrm{~nm}$, both similar to the InAs etch-stop layer in
Fig. 3a before the InGaSb was grown. Finally, at the highest $\mathrm{AHC}$ temperature of $400^{\circ} \mathrm{C}, \mathrm{AFM}$ reveals a significantly increased $\mathrm{rms}$ roughness of $2.1 \mathrm{~nm}$ with a peak-to-valley height of $31 \mathrm{~nm}$, as shown in Fig. 3c. Thus, for AHC temperatures between $280^{\circ} \mathrm{C}$ and $370^{\circ} \mathrm{C}$ and exposure durations $\leq 30 \mathrm{~min}$, InGaSb regrowth on $25 \AA$ InAs produces layer-bylayer growth, resulting in smooth surface morphologies. This is a very wide range of AHC conditions which result in high-quality films, with surface roughness limited only by the roughness inherited from the AlGaSb buffer layer. ${ }^{14}$

Improving the $p$-FET source and drain contact resistances is ultimately the goal for InGaSb regrowth in this work. Therefore, we have also investigated the electronic transport properties of the Be-doped InGaSb films. Table I presents a comparison of the electronic properties, including hole mobility, concentration, and resistivity, and the surface morphologies for InGaSb regrowth. In addition, Fig. 4 shows a comparison of the Hall resistivity and the surface roughness for InGaSb regrowth following $\mathrm{AHC}$ between $280^{\circ} \mathrm{C}$ and $400^{\circ} \mathrm{C}$, 
Table I. Comparison of the surface roughness, rms, and maximum peak-to-valley distance, P-V, determined from $10 \mu \mathrm{m} \times 10 \mu \mathrm{m}$ AFM images, and the hole mobility, $\mu$, hole concentration, $p$, and sheet resistance, $R_{\mathrm{SH}}$, determined from Hall measurements, for as-grown InAs, InGaSb grown on InAs without being removed from vacuum, and InGaSb regrowth on InAs following AHC at various temperatures and exposure times

\begin{tabular}{|c|c|c|c|c|c|}
\hline Sample & rms (nm) & P-V (nm) & $\mu\left(\mathrm{cm}^{2} / \mathrm{Vs}\right)$ & $p\left(10^{19} \mathrm{~cm}^{-3}\right)$ & $\boldsymbol{R}_{\mathrm{SH}}(\boldsymbol{\Omega} / \square)$ \\
\hline As-grown InAs & 1.57 & 12 & - & - & - \\
\hline InGaSb w/o regrowth & 1.68 & 14 & 77 & 3.3 & 1070 \\
\hline $280^{\circ} \mathrm{C}, 5 \mathrm{~min}$ & 1.61 & 14 & 110 & 2.8 & 870 \\
\hline $320^{\circ} \mathrm{C}, 5 \mathrm{~min}$ & 1.63 & 13 & 107 & 2.7 & 920 \\
\hline $350^{\circ} \mathrm{C}, 5 \mathrm{~min}$ & 1.61 & 12 & 109 & 2.6 & 960 \\
\hline $350^{\circ} \mathrm{C}, 60 \mathrm{~min}$ & 1.63 & 14 & 79 & 3.0 & 1150 \\
\hline $370^{\circ} \mathrm{C}, 5 \mathrm{~min}$ & 1.63 & 12 & 113 & 2.3 & 1050 \\
\hline $370^{\circ} \mathrm{C}, 30 \mathrm{~min}$ & 1.71 & 12 & 115 & 2.6 & 910 \\
\hline $370^{\circ} \mathrm{C}, 60 \mathrm{~min}$ & 1.81 & 17 & 94 & 2.3 & 1260 \\
\hline $400^{\circ} \mathrm{C}, 5 \mathrm{~min}$ & 2.09 & 31 & 82 & 2.2 & 1500 \\
\hline
\end{tabular}

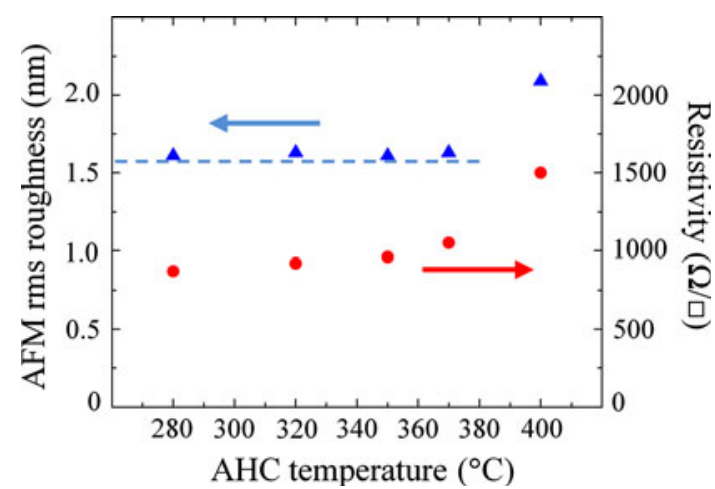

Fig. 4. (Color online). Hall resistivity in $\Omega / \square$ (red circles) and AFM rms roughness in $\mathrm{nm}$ (blue triangles), for $p^{+}$InGaSb regrowth on InAs following $5 \mathrm{~min}$ AHC at various substrate temperatures. The dashed line indicates the AFM rms roughness for as-grown InAs before AHC or InGaSb regrowth.

as well as for as-grown InAs. Again, we observe degradation of the electronic properties for $\mathrm{AHC}$ at $400^{\circ} \mathrm{C}$, as well as for durations of $60 \mathrm{~min}$. However, for regrowth following $5 \mathrm{~min}$ of $\mathrm{AHC}$ between $280^{\circ} \mathrm{C}$ and $370^{\circ} \mathrm{C}$, the Hall resistivity is actually lower than for InGaSb grown on InAs without being removed from vacuum, and the hole mobilities approach the highest reported to date for $p^{+}$III-V semiconductors. ${ }^{15}$ Thus, we have successfully fabricated high-quality $p^{+}$InGaSb regrowth layers, by inserting a thin InAs etch-stop layer after the AlGaSb. This method has great potential to lower the contact and access resistances for InGaSbchannel $p$-FETs, and is expected to be applicable for other antimonide-based semiconductor materials.

\section{CONCLUSIONS}

We have investigated regrowth of $p^{+}$InGaSb films on AlGaSb and InAs following atomic hydrogen cleaning surface treatments. For regrowth on $\mathrm{AlGaSb}$, issues resulting from residual Al-containing oxides and/or contaminants lead to multilayer
InGaSb growth with very rough surface morphology and very high resistivity. However, the insertion of a thin, $25 \mathrm{~A}$ InAs layer after the AlGaSb buffer layer results in significant improvements. Surface morphologies for InGaSb regrown on InAs following AHC exhibited similar AFM rms roughness to the asgrown InAs, which in turn was similar in roughness to the AlGaSb buffer below it. In addition, resistivities for InGaSb regrown on InAs were the same as, or better than, InGaSb grown on InAs without being removed from vacuum. A wide range of $\mathrm{AHC}$ conditions led to smooth InGaSb films with low resistivity, including substrate temperatures between $280^{\circ} \mathrm{C}$ and $370^{\circ} \mathrm{C}$ and exposure durations between $5 \mathrm{~min}$ and $30 \mathrm{~min}$.

\section{ACKNOWLEDGEMENTS}

The authors thank their collaborators at the Naval Research Laboratory, including J.G. Champlain, N.A. Papanicolaou, and D. Park. The Office of Naval Research supported this work.

\section{REFERENCES}

1. B.R. Bennett, R. Magno, J.B. Boos, W. Kruppa, and M.G. Ancona, Solid State Electron. 49, 1875 (2005).

2. R. Magno, J.G. Champlain, H.S. Newman, M.G. Ancona, J.C. Culbertson, B.R. Bennett, J.B. Boos, and D. Park, Appl. Phys. Lett. 92, 243502 (2008).

3. B.R. Bennett, M.G. Ancona, J.B. Boos, and B.V. Shanabrook, Appl. Phys. Lett. 91, 042104 (2007).

4. J.B. Boos, B.R. Bennett, N.A. Papanicolaou, M.G. Ancona, J.G. Champlain, R. Bass, and B.V. Shanabrook, Electron. Lett. 43, 834 (2007).

5. M. Walther, G. Kramer, R. Tsui, H. Goronkin, M. Adam, S. Tehrani, S. Rogers, and N. Cave, J. Cryst. Growth 143, 1 (1994).

6. M. Walther, G. Kramer, R. Tsui, H. Goronkin, M. Adam, S. Tehrani, S. Rogers, and N. Cave, J. Electron. Mater. 24, 387 (1995)

7. T. Baba, T. Uemura, and M. Mizuta, J. Cryst. Growth 127, 887 (1993)

8. G.R. Bell, N.S. Kaijaks, R.J. Dixon, and C.F. McConville, Surf. Sci. 401, 125 (1998).

9. T.M. Burke, M.A. Quierin, M.P. Grimshaw, D.A. Ritchie, M. Pepper, and J.H. Burroughes, J. Vac. Sci. Technol. B 15, 325 (1997). 
10. R. Hey, M. Wassermeier, M. Horicke, E. Wiebicke, and H. Kostial, J. Cryst. Growth 201, 582 (1999).

11. G.J. Burek, M.A. Wistey, U. Singisetti, A. Nelson, B.J. Thibeault, S.R. Bank, M.J.W. Rodwell, and A.C. Gossard, J. Cryst. Growth 311, 1984 (2009).

12. I. Horcas, R. Fernandez, J.M. Gomez-Rodriguez, J. Colchero, J. Gomez-Herrero, and A.M. Baro, Rev. Sci. Instrum. 78, 013705 (2007).
13. 1D Poisson-Schrödinger solver program developed by Dr. Gregory Snider, University of Notre Dame [http://www. nd.edu/ gsnider/].

14. B.R. Bennett, S.A. Khan, J.B. Boos, N.A. Papanicolaou, and V.L. Kuznetsov, J. Electron. Mater. 39, 2196 (2010).

15. J.G. Champlain, R. Magno, and J.B. Boos, J. Vac. Sci. Technol. B 24, 2388 (2006). 